\title{
Biology education research: building integrative frameworks for teaching and learning about living systems
}

Ross H. Nehm®

\begin{abstract}
This critical review examines the challenges and opportunities facing the field of Biology Education Research (BER). Ongoing disciplinary fragmentation is identified as a force working in opposition to the development of unifying conceptual frameworks for living systems and for understanding student thinking about living systems. A review of Concept Inventory $(\mathrm{Cl})$ research is used to illustrate how the absence of conceptual frameworks can complicate attempts to uncover student thinking about living systems and efforts to guide biology instruction. The review identifies possible starting points for the development of integrative cognitive and disciplinary frameworks for BER. First, relevant insights from developmental and cognitive psychology are reviewed and their connections are drawn to biology education. Second, prior theoretical work by biologists is highlighted as a starting point for reintegrating biology using discipline-focused frameworks. Specifically, three interdependent disciplinary themes are proposed as central to making sense of disciplinary core ideas: unity and diversity; randomness, probability, and contingency; and scale, hierarchy, and emergence. Overall, the review emphasizes that cognitive and conceptual grounding will help to foster much needed epistemic stability and guide the development of integrative empirical research agendas for $\mathrm{BER}$.
\end{abstract}

Keywords: Biology education research, Biology education, Discipline-based education research, Conceptual frameworks, Cognition, Life science

\section{Introduction}

Many policy documents emphasize that student understanding of living systems requires the integration of concepts that span levels of biological organization, encompass the tree of life, and cross different fields of study (AAAS, 2011; NRC, 2009; NSF, 2019). Yet the institutional, disciplinary, and curricular structuring of the life sciences often works in opposition to these pursuits. More so than in physics and chemistry, "biology" encompasses an expansive array of disciplines, each of which is often housed in a different academic department (e.g., microbiology, botany, genetics). These disciplines often organize into different academic societies, communicate through different journals, embrace different methodological frameworks,

Correspondence: ross.nehm@stonybrook.edu

Department of Ecology and Evolution, Institute for STEM Education, Stony Brook University (SUNY), 650 Life Sciences Building, Stony Brook, New York 11794-5233, USA

(c) The Author(s). 2019 Open Access This article is distributed under the terms of the Creative Commons Attribution 4.0 International License (http://creativecommons.org/licenses/by/4.0/), which permits unrestricted use, distribution, and reproduction in any medium, provided you give appropriate credit to the original author(s) and the source, provide a link to the Creative Commons license, and indicate if changes were made. and gather at separate scientific conferences. Such fragmentation is evident at many universities, which lack "biology" departments altogether, and may instead be organized by taxonomy (e.g., botany, zoology, microbiology departments), concept (e.g., genetics, ecology, evolution departments), unit or scale (e.g., cell biology, biochemistry). There is no organizational blueprint characteristic of biology departments in the United States, for example. Given that most universities have not identified a singular solution for structuring the life sciences, it is unsurprising that diverse structures also characterize biology education research. Disciplinary (and corresponding educational) fragmentation works against attempts at fostering an integrative understanding of living systems for students, which is arguably a foundational goal of biology education. 
In this critical review I examine some of the conceptual challenges facing the field of Biology Education Research (BER). These challenges reflect the substantial disciplinary fragmentation of BER, but they also highlight opportunities for advancing student understanding of living systems. I focus on the conceptual foundations of the discipline because they are a unique feature of biology education and have received substantially less attention than education practices (e.g., active learning, course-based research experiences, inclusive pedagogies). I begin by documenting the disciplinary fragmentation of the biological sciences and the corresponding heterogeneity and conceptual fragmentation of BER efforts. A consequence of such compartmentalization has been the lack of attention to the development and testing of unifying conceptual frameworks for (i) living systems and (ii) student thinking about living systems (in contrast to individual concepts, such as mutation, heredity, or genetic drift). This finding aligns with prior reviews that have also noted limited empirical-theoretical coordination within BER. The lack of attention to unifying frameworks for both biology and BER has consequences for biology education. A review of Concept Inventory (CI) research is used to illustrate how the absence of robust conceptual frameworks can complicate attempts to uncover student thinking about living systems and to guide biology instruction. The reviews of BER scholarship and CIs are used to motivate discussion of possible blueprints for BER-specific frameworks. First, findings from developmental and cognitive psychology are proposed as central to the development of cognitive frameworks. Second, possible disciplinary frameworks for BER are proposed after summarizing attempts by biologists to establish unifying themes for living systems that transcend individual subdisciplines. These themes include unity and diversity; randomness, probability, and contingency; and scale, hierarchy, and emergence. The review ends by emphasizing that the most significant opportunity for strengthening and unifying BER lies in the formulation of conceptual frameworks that account for how learners make sense of living systems as they progress through ontogeny and formal education. Such frameworks are much-needed tools for organizing and executing field-specific disciplinary research agendas.

\section{The disciplinary structures of biology and biology education research}

Many journals focus on BER and have grown out of the disciplinary structures and educational needs of academic departments; this history helps to make sense of the fragmented structure currently characterizing BER. Many biological disciplines have produced associated educational journals that serve as examples: Microbiology (Journal of Biology and Microbiology Education),
Evolution (e.g., Evolution: Education and Outreach), and Neuroscience (e.g., Journal of Undergraduate Neuroscience Education) (see Table 1). In many respects, this situation mirrors the explosion of discipline-specific journals in the life sciences.

Many of the research questions addressed within BER subdisciplines are an outgrowth of the educational contexts in which biological specialists have worked. The pressure to update curricula to reflect discipline-specific advances, for example, is a challenge inherent to all of the biological sciences (perhaps to a greater degree than in introductory physics and chemistry, where the content has remained relatively stable for the past century). Indeed, entirely new research areas (e.g., microbiomes, ancient DNA [deoxyribonucleic acid]) and methods (e.g., bioinformatics, CRISPR [clustered regularly interspaced short palindromic repeats]) emerge with increasing tempo each decade. Keeping students up-to-date with discipline-specific understanding is an ongoing challenge that has spurred educational reform, innovation, and ongoing professional development within biological subdisciplines (e.g., physiology) and their associated journals.

A second feature of the fragmented nature of biology education is the seemingly unique learning challenges that have been identified within each disciplinary context (e.g., microbiology, evolution, genetics). The challenge of addressing the student misconception that bacteria are primarily pathogenic, for example, is of particular concern within microbiology; developing approaches to tackle goal-driven reasoning about evolutionary change is central to evolution education; and helping students recognize the genetic similarity of eye cells and liver cells is foundational to genetics and genomics. Many educational efforts in biology education have arisen from attempts to tackle domain-specific learning challenges, including the development of tools for diagnosing topicspecific misunderstandings (see Student Thinking about Living Systems, below). Perhaps as a consequence of disciplinary isolation, markedly less work in BER has sought to identify common threads in the fabric of student confusion and to weave them into unified models of biological reasoning that are capable of explaining seemingly disparate educational challenges (although see Coley \& Tanner, 2012; Opfer et al., 2012, for cognitionbased examples of such efforts).

The fragmentation of BER efforts and journals could be viewed as an historically contingent outcome of the disciplinary structure of the biological sciences and the unique challenges that characterize them. But a less myopic view might reveal cross-cutting commonalities across disciplines (see below). Indeed, recent efforts in the United States and elsewhere have attempted to reform the biology curriculum and highlight cross-cutting 
Table 1 Examples of Biology Education Research (BER) journals aligned with particular disciplines or targeted to particular groups of biological specialists. Note that CBE-Life Sciences Education has evolved to encompass a much broader audience of biology educators

\begin{tabular}{lll}
\hline Discipline & Journal example & Web address of journal \\
\hline Biochemistry & Biochemistry and Molecular Biology Education & https://iubmb.onlinelibrary.wiley.com/journal/15393429 \\
Microbiology & Journal of Biology and Microbiology Education & http://www.asmscience.org/content/journal/jmbe \\
Neurobiology & Journal of Undergraduate Neuroscience Education & http://www.funjournal.org/ \\
Physiology & Advances in Physiology Education & https://www.physiology.org/journal/advances \\
Cell Biology & CBE-Life Sciences Education & https://www.lifescied.org/ \\
Evolution & Evolution: Education and Outreach & https://evolution-outreach.biomedcentral.com/ \\
Ecology & Teaching Issues and Experiments in Ecology & https://tiee.esa.org/ \\
Crops/Soils & Natural Sciences Education & https://dl.sciencesocieties.org/publications/nse \\
Biology & The American Biology Teacher & http://abt.ucpress.edu/ \\
Biology & Journal of Biological Education & https://www.tandfonline.com/loi/rjbe20 \\
\hline
\end{tabular}

concepts that undergird many different subdisciplines (e.g., Vision and Change in Undergraduate Biology Education, AAAS, 2011). Efforts have also been made to bring different biology education communities together under new organizational arrangements (e.g., SABER: Society for the Advancement of Biology Education Research; ERIDOB: European Researchers In the Didactics Of Biology). Following these biology-specific unification efforts, the National Research Council (2012) has also attempted to define and unite the efforts of chemistry, physics, and biology education researchers under the umbrella of "Discipline-Based Educational Research" (DBER). It is clear that the disciplinary structure of biology education, like that of other educational research disciplines, is in flux. Attempts to integrate pockets of disciplinary research activity is ongoing, and it is too soon to characterize the outcomes of these efforts. But disciplinary unification is often fostered by conceptual frameworks that encompass the needs and goals of stakeholders (Miller, 1978). Such work will be invaluable for guiding educational integration.

In summary, the range and diversity of BER journals and research efforts (Table 1) continue to mirror the tangled disciplinary and academic roots from which they grew. Unifying the paradigms and perspectives being generated from multiple BER journals and scientific societies is challenging, yet a worthy goal if true conceptual unification into a "BER community" (or an even larger "DBER community") is to be achieved. In the following sections, some cross-cutting themes from this expansive body of work are identified, reviewed, and critiqued. Much like BER itself, there are many alternative frameworks that could effectively characterize this evolving area of scholarship. But a persistent question that emerges from a review of this fractured body of work is whether there are sufficient conceptual and theoretical frameworks capable of supporting the challenge of disciplinary unification (and corresponding educational unification).

\section{Conceptual and theoretical frameworks for biology education research}

Theory building linked to causal explanation is a central goal of scientific and social-science research, although the two fields often differ in the number of theories used to explain particular phenomena. In both realms "... research emanates from the researcher's implicit or explicit theory of the phenomenon under investigation" (Rocco \& Plakhotnik, 2009, p. 121). Therefore, clear specification of theoretical framing and grounding is essential to the research enterprise (Imenda, 2014). A question in need of attention is what conceptual or theoretical frameworks help to frame, ground, and unite BER as a standalone field of educational inquiry (cf. Nehm, 2014)? Two of the more recent reviews of BER history and scholarship are notable in that they did not identify (or propose) discipline-specific educational frameworks (Dirks, 2011; deHaan, 2011). In her characterization of BER studies from 1990 to 2010, for example, Dirks (2011) identified three categories of scholarship: (1) student learning or performance, (2) student attitudes and beliefs, and (3) concept inventories and validated instruments. Within each category, Dirks examined the theoretical frameworks that were used to guide the empirical work that she reviewed. Few studies in these three categories linked empirical investigations to explicit theoretical frameworks. Instead, BER scholars framed their investigations in terms of 'problem description.' In cases where theoretical frameworks were hinted at, they were quite general (e.g., Bloom's Taxonomy, Ausubel's emphasis on prior knowledge and learning). The vast majority of studies in Dirks's (2011) review lacked disciplinebased educational framing and conceptual grounding, and no BER-specific theoretical frameworks were identified. 
deHaan's (2011) review of the history of BER also touched upon the theoretical frameworks that have been used to guide BER. Three frameworks--constructivism, conceptual change, and "others" (i.e., social interdependence and theories of intelligence)--were identified. It is notable that these frameworks did not originate within BER (they are frameworks developed in education and psychology) and they are not discipline-specific (i.e., educational frameworks unique to BER). Although not inherently problematic, one might expect (or indeed require) a discipline-focused educational enterprise to pursue and establish discipline-focused frameworks. If such frameworks are lacking, then the question arises as to what unifies and organizes the pursuits of affiliated scholars. A superficial, a-theoretical, and unsatisfying answer to this question could be that "BER focuses on biology education." Overall, these reviews and a corresponding examination of studies from a variety of journals (Table 1 ) suggest that BER typically lacks discipline-specific conceptual or theoretical frameworks.

Although many BER studies lack explicit anchoring in conceptual or theoretical frameworks unique to living systems, some work has attempted to build such frameworks. Conceptual frameworks for the disciplinary core ideas of (i) information flow in living systems and (ii) evolutionary change illustrate how different concepts and empirical findings may be related to one another and integrated into a framework that explains, predicts, and guides research in biology education (Fig. 1). Shea et al. (2015), for example, elaborated on Stewart et al.'s (2005) genetics literacy model and presented a tripartite framework showing the interrelationships among content knowledge use, argumentation quality, and the role of item surface features in genetic reasoning (Fig. 1a). This conceptual framework is biology-specific (i.e., addresses student reasoning about the disciplinary core idea of information flow at various scales) and applicable to most living systems (i.e., attends to phylogenetic diversity). The addition of argumentation to this model is valuable but not necessarily unique to this topic (argumentation is a practice central to all of science). This framework is a useful example because it (i) synthesizes prior empirical work, (ii) explains why student reasoning about information flow may fail to reach performance expectations, (iii) guides future research agendas and associated studies, (iv) applies broadly to living systems, and (v) motivates the development of particular curricular and pedagogical strategies.

The second conceptual framework focuses on student reasoning about evolutionary change (Fig. 1b). Nehm (2018) presents a conceptual framework that integrates aspects of Information Processing Theory, empirical findings on novice-expert evolutionary reasoning, and student challenges with evolutionary mechanisms (Fig. 1b; see also Ha \& Nehm 2014; Nehm \& Ha, 2011, Nehm and Ridgway 2011). When encountering tasks (or situations) that prompt for explanations of evolutionary change, sensitivity to item features (e.g., familiar plant species that have or lack thorns) impacts internal problem representation, which in turn affects the recruitment of individual concepts and schemas from long-term memory into working memory. The utilization of

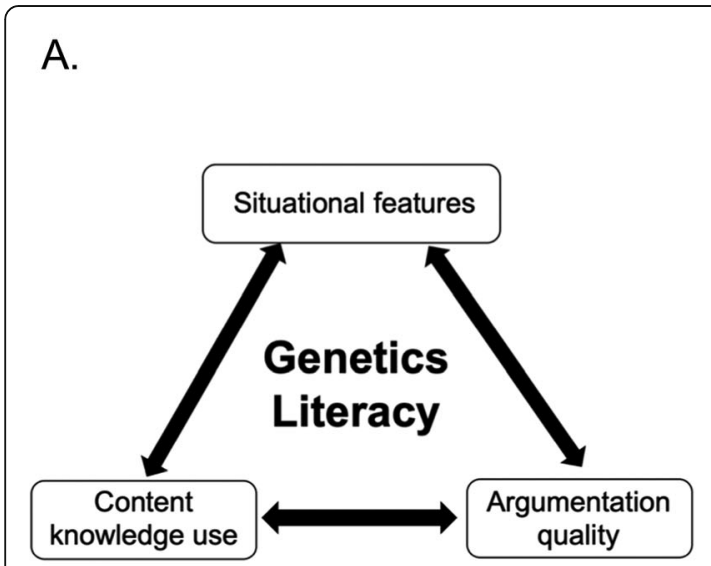

B. $\stackrel{E}{=}$

Taxon, trait,
polarity,

familiarity etc.

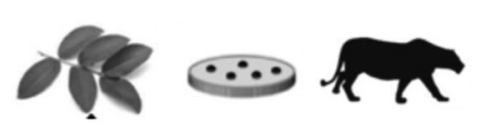

Written

explanation, oral

utterances

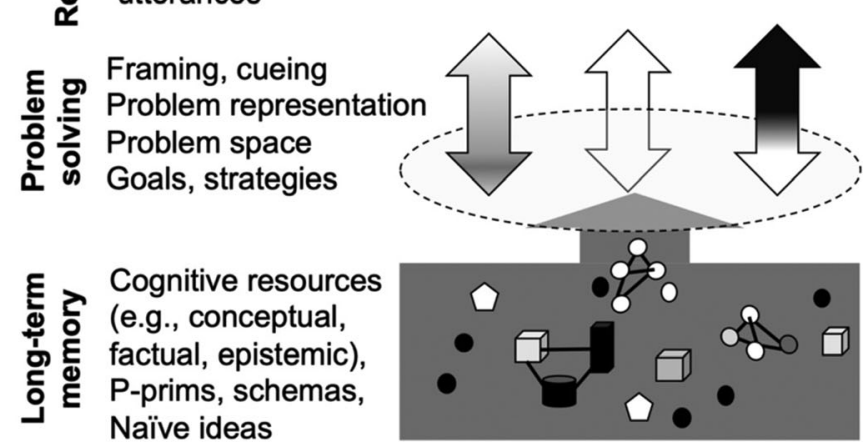

Fig. 1 Examples of conceptual frameworks developed for biology education research. a A three-part conceptual framework for genetics literacy encompassing situational features, content knowledge use, and argumentation quality (modified from Shea et al. 2015). b A conceptual framework for evolutionary reasoning encompassing long-term memory, problem-solving processes, and item features (similar to the situational features of Shea et al. 2015). Modified from Nehm (2018) 
different assemblages of cognitive resources is driven by the features of the living systems. Like Shea et al.'s (2015) conceptual framework, Nehm's (2018) conceptual framework (i) integrates existing theory (i.e., information processing theory) with prior empirical work, (ii) accounts for why student reasoning about evolutionary change may fail to reach performance expectations, (iii) guides future research agendas, and (iv) motivates the development of curricular and pedagogical strategies to address particular cognitive bottlenecks noted in the framework. Both of these frameworks attend to fundamental features of living systems (i.e., information flow, evolution) that transcend individual cases and exemplars (i.e., they consider diversity as a core feature of biological reasoning). Although both examples are simple, they organize a range of concepts central to understanding disciplinary thinking.

In summary, many factors work to maintain division among life science subfields (e.g., separate departments, conferences, journals, language; Table 1), and few counteracting factors promote unification (e.g., curricular cohesion, conceptual frameworks). Fragmentation of BER is an inevitable result. Interestingly, life scientists have long been concerned with a parallel challenge: the lack of attention to theoretical grounding and conceptual unification. The next section briefly reviews prior attempts to promote the development of conceptual frameworks for the life sciences. Although these frameworks do not address educational research specifically, they identify unifying concepts and principles that are essential starting points for building more robust conceptual foundations and frameworks for BER.

\section{Conceptual frameworks for biology and biology education research}

The past 60 years included several formal attempts to generate a conceptual framework for living systems and articulate a corresponding vision for the life sciences (e.g., Gerard and Stephens 1958; Miller, 1978; AAAS, 2011; NSF, 2019). The importance of theoretical foundations for biology was raised by Weiss (1958, p. 93): “... the question [is] whether present-day biology is paying too little attention to its conceptual foundations, and if so, why." In the 1950's, the Biology Council of the U.S. National Academy of Sciences invited eminent biologists (e.g., Rollin Hotchkiss, Ernst Mayr, Sewell Wright) to explore the conceptual foundations of the life sciences given apparent disciplinary fragmentation. The report that emerged from their discussions and deliberations (NRC, 1958) attempted to re-envision biology through a more theoretical lens and generate a conceptual and hierarchical reconceptualization of the study of life. Conceptually, it included the broad categories of "Methods," "Disciplines," and "Concepts." Methods organized life science research by the approaches used to generate understanding (e.g., immune tests, breeding, staining, factor analysis). Disciplines (structure [architecture, spatial relations, negative entropy]), and "Concepts" (history [origin]). Each of these categories-Methods, Disciplines, and Concepts--were then uniquely characterized at different biological scales (i.e., molecule, organelle, cell, organ, individual, small group, species, community/ecosystem, and total biota).

Three salient features of this early work include: (1) acknowledging the importance of conceptual grounding for the life sciences in light of disciplinary fragmentation; (2) situating academic topics and disciplines (e.g., anatomy, microbiology, ecology) within a conceptual superstructure (i.e., Structure, Equilibrium, History) and (3) highlighting the centrality of scale when considering life science Concepts, Methods, and Disciplines.

The U.S. National Research Council report Concepts of Biology (1958), while concerned with conceptual and disciplinary unification, did not lose sight of inherent connections to educational pursuits and outcomes: "Any success in improving the intellectual ordering of our subject would contribute to improved public relations, to the recruitment of more superior students, and to a better internal structure which would favor better teaching and research and in turn attract more students and support" (Weiss, 1958, p. 95). These and many other significant efforts (e.g., Miller, 1978) confirm that the struggle for conceptual and educational unification of the life sciences has been ongoing, and repeated calls for unity suggest that the successes of these early efforts have been limited.

Although the history of BER illuminates the deeper roots of disciplinary challenges (deHaan 2011), attention to recent progress should also be noted. The efforts to develop and deploy unified conceptual and curricular frameworks for biology education that mirror expert conceptualizations are ongoing (e.g., AAAS, 2011; NSF, 2019). In the United States, for example, the past two decades have witnessed substantial progress on how to structure and reform undergraduate and K-12 biology education. Emerging from interactions among many different stakeholders and scholars (see Brownell, Freeman, Wenderoth, \& Crowe, 2014, their Table 1) and mirroring curricular innovations by working groups of biologists (e.g., Klymkowsky, Rentsch, Begovic, \& Cooper, 2016) arose Vision and Change in Undergraduate Biology Education (AAAS, 2011) and, later, the Next Generation Science Standards (NRC, 2013). Both initiatives have attempted to winnow down the expansive range of biological topics that students experience and reorganize them into a more cohesive conceptual and curricular framework (much like NRC 1958 and Miller 1978). This framework is notable in that it continues to move the 
life sciences away from historically-based disciplinary structures focused on taxon (e.g., microbiology, botany, zoology) and towards more theoretical, principle-based schemes (e.g., structure and function) that transcend individual biological scales.

For example, Vision and Change reorganized biological knowledge according to five core concepts (AAAS, 2011, pp. 12-14): (1) Evolution (The diversity of life evolved over time by processes of mutation, selection, and genetic change); (2) Structure and Function (Basic units of structure define the function of all living things); (3) Information Flow, Exchange, and Storage (The growth and behavior of organisms are activated through the expression of genetic information in context); (4) Pathways and Transformations of Energy and Matter (Biological systems grow and change by processes based upon chemical transformation pathways and are governed by the laws of thermodynamics); and (5) Systems (Living systems are interconnected and interacting). Many of these ideas are in alignment with previous conceptual work by Gerard and Stephens (1958) and Miller (1978). Vision and Change, however, provides a very limited characterization of these core concepts and does not explicitly discuss their interrelationships across biological scales (e.g., gene, organism, species, ecosystem).

The BioCore Guide (Brownell et al., 2014) was developed to provide more fine-grained and longer-term guidance for conceptualizing and implementing the goals of Vision and Change. Specifically, principles and statements were derived for each of the five Vision and Change core concepts in order to structure undergraduate degree learning pathways (Brownell et al., 2014). Efforts have also been made to stimulate change within institutions. Partnership for Undergraduate Life Science Education (PULSE Community, 2019), for example, has been developed to encourage adoption of these curricular innovations and self-reflection by life science departments.

Collectively, these conceptually-grounded curriculum frameworks (e.g., Vision and Change, BioCore) and associated reform efforts (PULSE) are important, new unifying forces counteracting the fragmented structure of the biological sciences. They also form necessary (but insufficient) substrates for constructing conceptual frameworks for BER. They are insufficient because, from an educational vantage point, identifying the concepts, schemas, and frameworks of a discipline is only one aspect of the challenge; these ideas must articulate in some way with how students think, reason, and learn about biological concepts and living systems. The next section reviews progress and limitations of biology educators' attempts to understand student thinking about living systems in light of these disciplinary frameworks (e.g., NRC, 1958; Miller, 1978; AAAS, 2011).

\section{Student thinking about living systems}

Educational efforts to foster cognitive and practice-based competencies that align with disciplinary frameworks (such as Vision and Change) must consider what is known about student thinking about living systems. It is therefore essential to consider how the BER community has approached this challenge, what they have learned, and what remains to be understood about living systems (e.g., NRC, 1958; Miller, 1978; AAAS, 2011).

The absence of robust conceptual and theoretical frameworks for the life sciences has not prevented teachers and educational researchers from different disciplinary backgrounds (e.g., microbiology, ecology) from identifying domain-specific learning challenges and misunderstandings (Driver et al. 1994; Pfundt \& Duit, 1998; NRC, 2001). Hundreds of individual concepts (e.g., osmosis, recombination, genetic drift, trophic levels, global warming) are typically presented to students in textbooks and taught in classrooms (NRC, 1958). Biology teachers have correspondingly noticed, and biology researchers have empirically documented, an array of misunderstandings about these individual concepts and topics (for reviews, see Pfundt \& Duit, 1998; Reiss and Kampourakis 2018). When attempting to solve biological problems, for example, many university students: convert matter into energy in biological systems; adopt useand-disuse inheritance to explain changes in life over time; and account for differences between eye and liver cells as a result of DNA differences. Many of the same misunderstandings have been documented in young children (Driver, Squires, Rushworth, \& WoodRobinson, 1994; Pfundt \& Duit, 1998).

The ubiquity and abundance of these non-normative conceptions and reasoning patterns has led biology educators in different subfields (see Table 1) to develop concept-specific assessment tools or instruments (socalled "Concept Inventories") in order to document the ideas (both normative and non-normative) that students bring with them to biology classrooms (Table 2). For particular topics or concepts, researchers have consolidated studies of student misunderstandings by category (e.g., Driver et al., 1994; Pfundt \& Duit, 1998), confirmed and refined descriptions of these misunderstandings using clinical interviews, and developed associated suites of assessment items relevant to a particular idea (i.e., concept, principle).

CIs typically contain items offering one normative scientific answer option along with a variety of commonly held misconception foils. These instruments are designed for instructors to uncover which non-normative ideas are most appealing to students and measure general levels of normative understanding. CIs have been developed for many topics in the biological subfields of cell biology, genetics, physiology, evolution, and ecology. 
Table 2 Examples of Concept Inventories (Cls) targeting different biological disciplines and topics

\begin{tabular}{|c|c|c|c|}
\hline Discipline & Topic & Concept Inventory & Citation \\
\hline $\begin{array}{l}\text { Cell } \\
\text { biology }\end{array}$ & Meiosis & MCl: Meiosis Concept Inventory & Kalas, O’Neill, Pollock, and Birol (2013) \\
\hline $\begin{array}{l}\text { Cell } \\
\text { biology }\end{array}$ & Osmosis and diffusion & Osmosis and Diffusion Conceptual Assessment & Fisher, Williams, and Lineback (2011) \\
\hline Physiology & Homeostasis & $\mathrm{HCl}$ : Homeostasis Concept Inventory & $\begin{array}{l}\text { McFarland, Price, Wenderoth, Martinková, and } \\
\text { Cliff (2017) }\end{array}$ \\
\hline Physiology & $\begin{array}{l}\text { Photosynthesis and } \\
\text { respiration }\end{array}$ & Unnamed: Two-tier multiple-choice instrument & Haslam and Treagust (1987) \\
\hline Genetics & Various ideas & GCA: Genetics Concept Assessment & Smith, Wood, and Knight (2008) \\
\hline Genetics & Dominance & DCl: Dominance Concept Inventory & Abraham, Perez, and Price (2014) \\
\hline Genetics & The central dogma & CDCl: Central Dogma Concept Inventory & Newman, Snyder, Fisk, and Wright (2016) \\
\hline Genetics & Lac Operon & LOCI: Lac Operon Concept Inventory & Stefanski, Gardner, and Seipelt-Thiemann (2016) \\
\hline Evolution & Evolutionary Change & $\begin{array}{l}\text { ACORNS: Assessment of COntextual Reasoning about } \\
\text { Natural Selection }\end{array}$ & Nehm, Beggrow, Opfer, and Ha (2012) \\
\hline Evolution & Genetic Drift & GEDI: GEnetic Drift Inventory & Price et al. (2014) \\
\hline
\end{tabular}

The number of biology CIs continues to grow each year, providing valuable tools for uncovering student thinking about specific biological ideas (Table 2).

Biology CIs have advanced prior work on student misconceptions (Pfundt \& Duit, 1998) by: (1) focusing attention on the core ideas of greatest importance to concept or topic learning (e.g., osmosis and diffusion), (2) attending to a broad range of common misunderstandings (previously identified in a variety of separate studies), (3) quantitatively documenting student understanding using large participant samples (in contrast to smaller-scale, qualitative studies); and (4) establishing more generalizable claims concerning students' mastery of biology concepts (facilitated by easy administration and multiple-choice format). As noted by Dirks (2011), concept inventory development was an important advance for the BER community by helping biologists recognize the ubiquity of biology misunderstandings and learning difficulties throughout the educational hierarchy.

Given the importance of $\mathrm{CI}$ development to BER (Dirks, 2011; see above), a critical review of this work is in order. I identify six limitations in order to illustrate some of the remaining challenges to understanding student thinking about living systems. The first major limitation of BER CI development is that it continues to be largely descriptive, a-theoretical, and lacking in explicit grounding in cognitive or conceptual frameworks (BERspecific or otherwise) (e.g., NRC, 2001). I will illustrate the practical significance of frameworks for living systems and theoretical frameworks for measurement using the National Research Council's (2001) "assessment triangle". In brief, the assessment triangle encompasses the three most central and necessary features for embarking upon studies of student understanding (and
CI development): cognition, observation, and interpretation (as well as interconnections thereof; see Fig. 1). Cognition refers to the relevant features and processes of the cognitive system that are used to frame and ground the development of assessment tasks. Observation refers to the tangible artifacts (e.g., verbal utterances, written text, diagrams) that are generated as a result of engaging with such tasks. Interpretation refers to the inferences drawn from analyses of the observations produced by the tasks.

All three corners of the assessment triangle are inextricably interrelated (Fig. 1). For example, interpretation relies on appropriate analyses of the observations, and the observations only have meaning when viewed in light of the cognitive models used to construct the assessment tasks. Misinterpretations and faulty inferences about student understanding may arise from implicit and unexamined (or false) assumptions at any corner of the triangle (e.g. inappropriate tasks, inappropriate analyses of observations, inappropriate theoretical grounding). The NRC assessment triangle identifies the central features involved in making inferences about student reasoning (e.g., reasoning about biological systems). Remarkably few biology CIs have attended to all of these central features.

The cognition corner of the NRC's (2001) assessment triangle demands focused attention on what is known about how students conceptualize and process information in general and biological systems in particular. That is, theories of cognition and theories of biological reasoning should undergird and support claims about what CI tasks are seeking to capture. The majority of CIs examined lack grounding in well-established theories of cognition (e.g., information processing theory, situated cognition theory) or theories of biological thinking and reasoning (e.g., categorization of living vs. non-living; see 
below). As a result, the necessary features of assessment design (Fig. 2) are lacking; this generates an unstable base for task design, data interpretation, and claims about biological thinking (Opfer et al., 2012).

A practical example may help to elucidate how the interplay among assessment triangle vertices impact claims drawn from CIs. Consider the role that the diversity of life might play in biological reasoning, for example. If the cognitive model (e.g., information processing theory) undergirding $\mathrm{CI}$ task design assumes that students will activate different ideas depending upon the taxon used in the assessment task (e.g., plant, non-human animal, human animal, fungus, bacteria), then multiple taxonomic contexts will be necessary in order to gather relevant observations and to draw robust inferences about how students think. If, on the other hand, the cognitive model assumes that students process information using abstractions of concepts, then attention to taxonomy in task design is unnecessary and most biological exemplars will suffice. The items that are developed and the corresponding scores that emerge from these two different cognitive perspectives are likely to be different. Cognition, observation, and interpretation (Fig. 2) emerge as necessary considerations in biology CI development, implementation, and score interpretations. Most CIs (Table 2) lack explicit alignment with the NRC's (2001) assessment triangle, contain implicit or unexamined cognitive assumptions, and as a result may generate ambiguous or debatable claims about student thinking about living systems (and, ultimately, cloud the field's attempt to make sense of how students think about living systems) (Tornabene, Lavington, \& Nehm, 2018).

In addition to the lack of attention to theoretical grounding (i.e., NRC, 2001), a second limitation of CIs relates to their practical utility for biology education (Table 3). Given that hundreds of topics are typically included in textbooks and taught in biology classes (NRC, 1958), and dozens of CIs have now been developed (e.g., Table 2), the question arises as to what to do with them; what, in other words, is the broader aim of building this expansive test battery? Assessing all of the major domains for which CIs have been developed would require substantial amounts of time and effort. Devoting class time to all of the biological preconceptions and alternative conceptions uncovered by all of these instruments would require eliminating many other learning objectives or reorganizing biology instruction. The field has not developed practical strategies for aligning the numerous isolated insights generated from CIs with the practical realities of instruction, or the broader goals for BER.

One practical solution for making use of the broad array of CIs would be to develop and deploy Computer Adaptive Tests (CATs) capable of automatically diagnosing levels of conceptual understanding (as opposed to administering all assessment items from all of the CIs) and delivering personalized instructional resources aligned with documented learning difficulties. These digital tools could be provided as pre-class assignments or as supplemental resources. Another solution more closely tied with the focus of this critical review would be to identify learning challenges apparent across CIs (e.g., difficulties in reasoning about living systems) and to develop corresponding instructional materials to address these broader misunderstandings or promote cognitive coherence. This approach circles attention back to the question of how conceptual frameworks for biology and biology education could be leveraged to unify understanding of diverse misconceptions across subdisciplines (see Conceptual and Theoretical Frameworks for Biology Education Research, above).

A third limitation of biology CIs relates to the design of assessment tasks and the inferences that are drawn

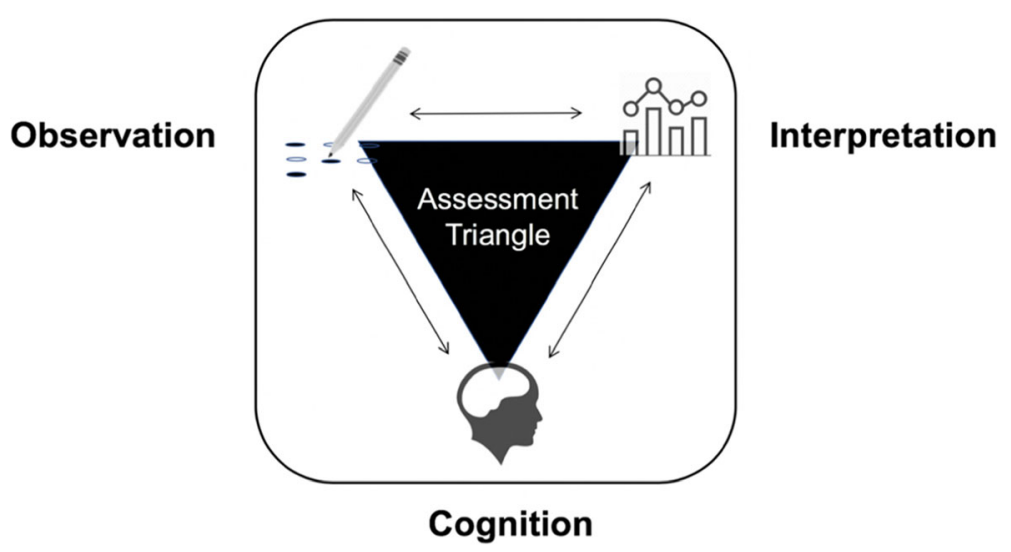

Fig. 2 The NRC Assessment Triangle. Measurement and assessment of student understanding requires the integration of cognitive models, observations, and interpretations of observations in light of cognitive models. Models of thinking about living systems-the cognition corner-are therefore crucial to the development, application, and evaluation of assessments 
Table 3 Uncovering Student Thinking about Living Systems. Concept Inventories (Cls) and their associated design solutions for the valid assessment of biological understanding in light of the assessment triangle

\begin{tabular}{lll}
\hline Concept Inventory Limitation & Description of limitation & Design solution to limitation \\
\hline $\begin{array}{l}\text { Embarking on assessment } \\
\text { design without a robust and } \\
\text { explicit cognitive framework. }\end{array}$ & $\begin{array}{l}\text { Assessment design does not consider the cognitive } \\
\text { theories that are implicitly being assumed when eliciting } \\
\text { observations from assessment tasks. }\end{array}$ & $\begin{array}{l}\text { Integrate theoretical work in developmental and } \\
\text { cognitive psychology with the NRC (2001) assessment } \\
\text { triangle to start assessment design with theoretical } \\
\text { grounding. }\end{array}$ \\
$\begin{array}{ll}\text { Offering only either-or item } \\
\text { structure (concepts vs. miscon- }\end{array}$ & $\begin{array}{l}\text { Mixtures of correct and incorrect ideas have been shown } \\
\text { to be common or the norm in some domains. }\end{array}$ & $\begin{array}{l}\text { Multiple-True-False formats in which all options may be } \\
\text { selected as correct or incorrect. }\end{array}$
\end{tabular}
ceptions) but not both. Using pieces to infer holistic
reasoning.

Situating tasks in one context or no context.

Prioritizing recognition over recall.

Interpreting observations using outdated psychometric models and sampling.
Selection of all of the normative pieces of an idea does not necessarily indicate that the pieces are assembled, understood, or applied in a normative manner.

Items typically measure knowledge in one situation, whereas studies show that students often display different understandings across contexts. Or, items measure knowledge in an abstract, generalized situation but not in a real-world context.

Recognizing information is a different cognitive process that recalling information. Nearly all Cls ask students to recognize the accuracy of information but do not have them construct or recall understanding of a concept.

Classical Test Theory has many limitations that can distort interpretations of instrument scores. Rasch and IRT methods offer significant advantages.
Ordered Multiple Choice formats present different arrangements and combinations of ideas reflective of levels of understanding or expertise. Assesses holistic understanding.

Measure knowledge across at least two situations or contexts (e.g., different taxa, different cell types) to determine stability or robustness of knowledge.

Constructed response assessments are well-suited to measuring knowledge via recall. Computerized scoring of responses is becoming more common, eliminating the drawbacks of time-intensive human scoring.

Gather sufficient sample sizes across diverse participant samples to foster robust interpretations of biological understanding or attitudes. from their scores. When employing open-ended assessment tasks and clinical interviews, some BER research has shown that a majority of students utilize mixtures of normative and non-normative ideas together in their biological explanations (Nehm \& Schonfeld, 2008, 2010). Most CI instrument items nevertheless continue to employ multiple-choice (MC) formats and only permit students to choose between a normative or a nonnormative answer option. This format may, in turn, introduce noise into the measurement process and weaken validity inferences. Multiple-True-False (MTF) items are one solution to this problem. Using MTF formats, students are permitted to indicate whether they consider each answer option to be correct or incorrect, thereby breaking the task design constraint evident in either-or item options. This limitation is another example of how consideration of both cognition (i.e., mixed cognitive models exist) and task design ( $\mathrm{MC}$ vs. MTF) work together to impact the quality and meaning of inferences about biological thinking drawn from CI scores (i.e., observations).

A fourth limitation of BER CIs concerns the authenticity of the assessment tasks themselves. Most CIs assess pieces of knowledge using $\mathrm{MC}$ items. It is not clear if students who are able to achieve high scores (i.e., select the constellation of normative answer options across multiple items) understand the concept as a whole (Nehm \& Haertig, 2012). For example, just because students select the normative ideas of mutation, heritability, environmental change, and differential survival from a pool of normative and non-normative item options does not necessarily mean that they would assemble these ideas in a scientifically correct manner. A student could, for example, use the aforementioned ideas to build an explanation in which environmental change in a particular habitat causes heritable mutations which in turn help these organisms differentially survive. Thus, non-normative models may be assembled from normative "pieces." This is another example of how inferences about students' biological understandings are tied to assessment and cognitive frameworks.

One solution to this challenge is to utilize Ordered Multiple Choice (OMC) items. These items prompt students to choose from among explanatory responses integrating many normative and non-normative combinations (as opposed to asking students to select individual ideas or conceptual fragments). These explanatory models could be designed to mirror hypothesized levels of conceptual understanding or biological expertise (e.g., learning progressions). OMC items have the potential to capture more holistic and valid characterizations of student reasoning (see Todd et al., 2017 for an example from genetics).

A fifth limitation of biology CIs centers on the "interpretation" corner of the assessment triangle (Fig. 2); robust validation methods aligned with contemporary psychometric frameworks are often lacking in biology CI studies (Boone, Staver, \& Yale, 2014; Neumann, Neumann, \& Nehm, 2011; Sbeglia \& Nehm, 2018, 2019). Rasch Analysis and Item Response Theory (IRT) are 
slowly supplanting traditional Classical Test Theory (CTT) methods for biology CI validation. In addition to psychometric limitations, validation studies of many biology instruments remain restricted to singular educational settings or demographically-restrictive samples (Mead et al. 2019; Campbell \& Nehm, 2013). These methodological choices introduce uncertainty about the generalizability of CI score inferences across demographic groups, educational institutions, and international boundaries. Particular care must be made when drawing inferences from CI scores to inform instructional decisions or evaluate learning efficacy given these limitations (Table 3).

The sixth and final limitation of extant biology CIs returns to the topic of discipline-based conceptual frameworks. Few if any of the biology CIs and assessment instruments have been designed to target foundational disciplinary themes identified over the past 60 years (e.g., reasoning across biological scales) or the disciplinary formulations advanced in Vision and Change (AAAS, 2011). BER assessment tools remain aligned to concepts or topics characteristic of a particular subdiscipline, biological scale, or taxon (e.g., human animals). Despite significant progress in documenting concept understanding (and misunderstanding), biology educators have directed much less attention to assessing the foundational features of living systems that are most closely tied to disciplinary frameworks (i.e., NRC, 1958; Miller, 1978; AAAS, 2011). That is, analogous to many biology curricula, BER CI work has assembled a valuable but disarticulated jumble of information (in this case, lists of student learning difficulties) lacking deep structure or coherence.

In summary, a critical review of BER efforts to understand student thinking about living systems has revealed significant progress and significant limitations. Significant progress has been made in: identifying a range of important topics and concepts relevant to disciplinary core ideas; developing instruments that measure many of the learning difficulties uncovered in prior work (Table 2); and documenting widespread patterns of limited content mastery and numerous misunderstandings. Significant limitations have also been identified (Table 3). Many of the biology assessment tools lack: explicit grounding in psychometric and cognitive theory; task authenticity mirroring biological practice and reasoning; robust validation methods aligned with contemporary psychometric frameworks; robust inferences drawn from cognitively-aligned tasks; and implementation guidelines aligned with the practical realities of concept coverage in textbooks and classrooms. Collectively, much is now known about a scattered array of topics and concepts within biological subdisciplines; few if any tools are available for studying foundational and cross-disciplinary features of living systems identified by biologists over the past 60 years (e.g., identifying emergent properties across biological scales; considering stochasticity and determinism in biological causation; predicting biological outcomes using systems thinking; NRC, 1958; Miller, 1978; AAAS, 2011). BER requires discipline-specific frameworks that illuminate biological reasoning. Cognitive perspectives will be foundational to developing these frameworks.

\section{What cognitive frameworks could guide BER?}

A productive trend in BER involves efforts to link cognitive perspectives developed in other fields (e.g., education, psychology) with discipline-specific challenges characteristic of teaching and learning about living systems (Inagaki and Hatano, 1991; Kelemen and Rosset 2009). The fields of cognitive and developmental psychology serve as essential resources for understanding the roots of student reasoning about living systems. Developmental psychologists have generated many crucial insights into the foundations of human reasoning about living systems, including animacy, life, death, illness, growth, inheritance, and biological change (e.g., Opfer and Gelman 2010; Table 4). In particular, studies of human thinking have explored (1) whether ontogenetic development is characterized by reformulations of mental frameworks about living systems or by more continuous and less structured change, and (2) whether these early frameworks impact adult reasoning about living systems.

One of the more illuminating and well-studied examples of the linkages between cognitive and disciplinary frameworks concerns human thinking about plants (Opfer and Gelman 2010). Some psychologists consider the origins of biological thought to first emerge as young children ponder the question of what is alive and what is not (Goldberg \& Thompson-Schill, 2009). For example, it is well established that young children initially conceptualize and classify plants as non-living entities. As cognitive development proceeds, plants are reclassified into an expanded category of "living" (e.g., plants + animals). An important question is whether early reasoning about biological categories and phenomena plays a significant role in later learning difficulties--including those documented in university undergraduates.

Plants provide a useful example for drawing possible connections among cognitive development, biological reasoning, and discipline-based conceptual frameworks. Plants comprise a central branch on the tree of life and are essential for human existence (i.e., sources of matter and energy). Yet, plants have posed significant challenges for life science educators (Wandersee \& Schussler, 1999). These challenges range from students' lack of perception of plants altogether (coined "plant blindness") to fundamental misconceptions about how plants reproduce, 
Table 4 Examples of cognitive psychology studies exploring biological reasoning in young children and related learning challenges in young adults

\begin{tabular}{lll}
\hline Topic & Cognitive and/or developmental psychology study & Related studies from biology education research \\
\hline Living and nonliving & Opfer and Siegler (2004) & Driver et al. (1994) \\
Inheritance & Ware and Gelman (2014) & Kargbo, Hobbs, and Erickson (1980) \\
Inheritance & Solomon, Johnson, Zaitchik, and Carey (1996) & Driver et al. (1994) \\
IIIness & Raman \& Winer (2002) & Raman \& Winer (2002) \\
IIIness & Au, Sidle, and Rollins (1993) & Driver et al. (1994) \\
Evolution & Kelemen (2009) & Kampourakis (2013) \\
Ancestry & Poling and Evans (2002) & Catley and Novick (2009) \\
\hline
\end{tabular}

transform matter and energy, and impact the chemical composition of the atmosphere (Wandersee \& Schussler, 1999). The early reformulations of biological categories in young children--such as the reorganization of plants into the category of "living things"--appear to persist into adulthood.

A study by Goldberg and Thompson-Schill (2009, p. 6) compared reasoning about plants relative to other living (e.g., animal) and non-living (e.g., rock) entities in undergraduates and biology professors. Under time pressure, it took biology professors significantly longer to recognize plants as living things (compared to animals and non-living entities). Goldberg and Thompson-Schill noted that " $[\mathrm{t}]$ he same items and features that cause confusions in young children also appear to cause underlying classification difficulties in university biology professors." This case is not unique. Children's reasoning about other biological phenomena, such as teleofunctional biases, also display continuities with adult thinking about evolutionary change (e.g., Kelemen and DiYanni, 2005). Work in cognitive and developmental psychology indicate that young children's early formulations about living systems might not be "re-written", but instead persist into adulthood, require active suppression, and impact later learning. Ongoing research in cognitive and developmental psychology has great potential for enriching our understanding of thinking in young adults, and for providing deeper insights into the causes of entrenched biology misunderstandings that often appear resistant to concerted educational efforts.

Studies at the other extreme--expert biologists--also have great potential for informing the development of unifying cognitive frameworks for BER. Comparative studies of experts and novices in different subject areas have been central to understanding domain-general and domain-specific features of problem representation and problem-solving performance for nearly a century (reviewed in Novick and Bassok, 2012). Novice-expert comparisons have seen comparatively little use in BER, although some notable exceptions include studies in genetics (Smith, 1983), evolution (Nehm \& Ridgway,
2011), and genetically-modified organisms (Potter et al. 2017). These studies offer a range of insights into how novices and experts conceptualize problems, plan solutions, and utilize concepts and frameworks in problemsolving tasks. These insights could be leveraged to help elucidate expert frameworks of biological systems, as well as to identify conceptual, procedural, and epistemic barriers in novice reasoning. In a study of evolution, for example, novices performed poorly on problem-solving tasks not because of a lack of domain-specific knowledge, but because of the ways in which they used superficial task features (different organisms) to cognitively represent the problems at hand (i.e., in fundamentally different ways than the experts). Here the tension in student thinking about the unity and diversity of living systems is revealed-which is also a disciplinary idea unique to BER (Dobzhansky, 1973). Helping students perceive unity across the diversity of life emerges as a crucial (but often neglected) instructional goal. Comparing expert and novice problem-solving approaches could reveal unknown barriers to biology learning and illuminate potential features of a theoretical conceptualization of BER. These frameworks become central to the "cognition" corner of the assessment triangle (NRC, 2001) and efforts to design CIs and measure educational impact.

In addition to tracing the origination, persistence, and modification of cognitive structures about living systems through ontogeny and expertise, it is useful to ask whether the disciplinary organization of the biological sciences and associated degree programs, curricula, and textbook organizations (cf. Nehm et al., 2009) contribute to students' fragmented models of living systems (e.g., Botany courses and textbooks focus on plants; Microbiology courses and textbooks focus on bacteria; Zoology courses and textbooks focus on animals). Few biologists would doubt that taxon-specific learning outcomes are essential for understanding the unique aspects of particular living systems. But an unanswered question is whether an effective balance between diversity and unity been achieved, or whether the scales have been tipped towards a focus on diversity-grounded learning 
(and corresponding cognitive fragmentation in biology students). It is notable that most biology textbook chapters, courses, and degree programs maintain organizational structures at odds with most conceptual reformulations of the life sciences (e.g., NRC, 1958; Miller, 1978; AAAS, 2011). Resolving these contradictions may help to conceptualize a more unified and principled framework for BER.

In summary, one of the most underdeveloped areas of BER concerns the formulation of conceptual and theoretical frameworks that account for how learners make sense of the similarities and differences within and across living systems as they progress through ontogeny and educational experiences. Cognitive and developmental psychology provide rich but largely untapped resources for enriching cognitively-grounded frameworks. In addition to studies of biological reasoning in young children, studies of expert thinking also offer considerable promise for uncovering barriers to expert-like conceptualizations of living systems. Collaborations with cognitive and developmental psychologists, and greater application of expert-novice comparisons, will be essential to advancing the cognitive frameworks for assessment design, curriculum development, and BER research.

\section{What disciplinary frameworks could guide BER?}

Although frameworks and models from psychology will be invaluable for crafting cognitive frameworks for BER, there are unique features of living systems that must also be explicitly considered in light of more broadly applicable cognitive models. To foster disciplinary unification and more integrative models of BER, these features should (1) span different biological subdisciplines and (2) undergird broad learning challenges about core ideas about living systems. Three areas--unity and diversity; randomness, probability, and contingency; and scale, hierarchy, and emergence-are likely to be valuable ideas for the development of discipline-grounded conceptual frameworks for BER. Each is discussed in turn below (Fig. 3).

\section{Unity and Diversity in biological reasoning}

A foundational (yet undertheorized) disciplinary challenge inherent to BER concerns the development of conceptual models of student sensemaking about the similarities and differences within and across living systems (NRC 1958; Klymkowsky et al., 2016; Nehm, 2018; Nehm et al., 2012; Shea, Duncan, \& Stephenson, 2015). A key argument often missed in Dobzhansky's (1973) seminal paper expounding the importance of evolution to all of biology was " $\mathrm{t}$ ] he unity of life is no less remarkable than its diversity" (p. 127). Indeed, a core goal of all biological disciplines is to develop and deploy causal models that transcend particular scales, lineages, and phenomenologies. Biology educators have, for the most part, documented myriad student learning difficulties within disciplinary contexts (e.g., microbiology, heredity, evolution, ecology) that are likewise bound to particular scales, concepts, and taxonomic contexts. Much less work has explored reasoning across these areas and the extent to which conceptual unity is achieved as students progress through biology education (Garvin-Doxas \& Klymkowsky, 2008).

A core need for BER is the development of explicit models of how student understanding of living systems

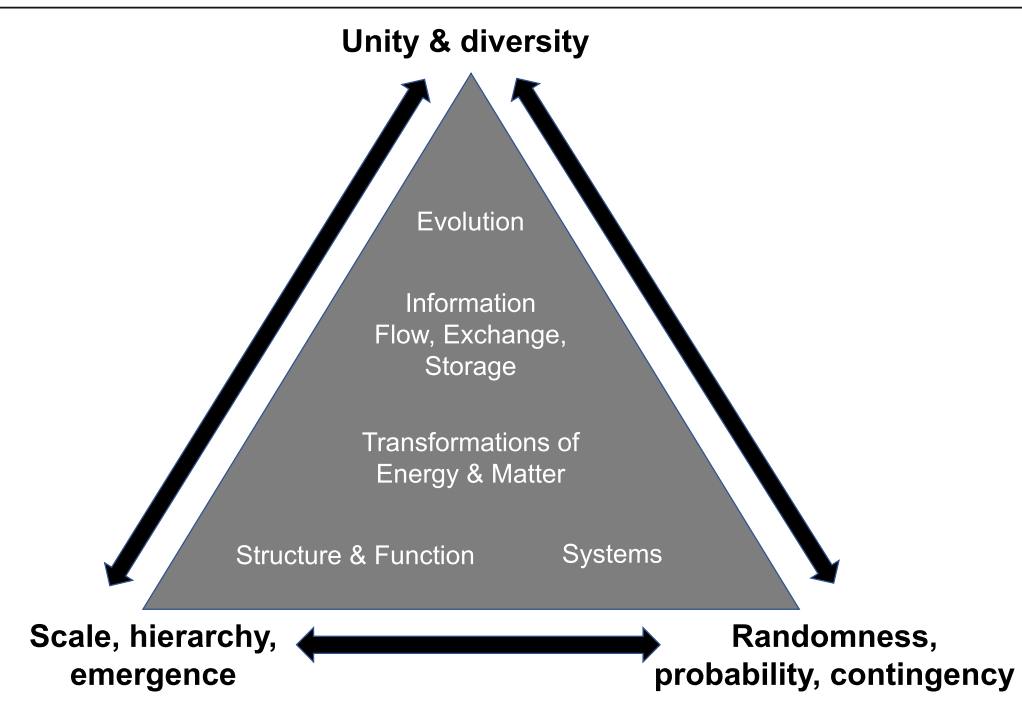

Fig. 3 Integrating conceptual frameworks into BER: student reasoning about unity and diversity; scale, hierarchy, and emergence; and randomness, probability, and historical contingency. Note that all three ideas interact to generate understanding about living systems, including processes within them (e.g., information flow) 
changes in response to formal and informal educational experiences (e.g., exposure to household pets, gardens, books, zoos, digital media, formal schooling). Throughout ontogeny, learners experience a wide range of life forms and their associated phenomenologies (e.g., growth, function, behavior, death). As learners engage with the diversity of the living world, a foundational question for BER is whether students construct increasingly abstract models of living systems (i.e. conceptual unity) or whether their sense-making remains rooted in taxonomic contexts, experiential instances, and case examples (i.e. conceptual diversity; Fig. 4).

The limited body of work exploring student reasoning about the unity and diversity of living systems has uncovered different findings. In some cases, research suggests that in older children and young adults, reasoning about living systems may remain highly fragmented and taxon-specific at particular scales (Fig. 4a; e.g., Freidenreich et al. 2011; Kargbo et al., 1980; Nehm \& Ha, 2011). In other cases, research has shown that student reasoning may develop into unified problem-solving heuristics within a biological scale (Fig. 4b; e.g., Schmiemann et al., 2017). Much less work has explored student reasoning about biological phenomena across biological scales (Fig. $4 c, d)$. Work in genetics education suggests that crossing these ontological levels or scales is inherently challenging for students (Freidenreich et al. 2011; Kargbo et al., 1980; Nehm \& Ha, 2011; Nehm, 2018). For example, students may develop conceptual understanding within a biological level (Fig. 4c) but be unable to conceptually link processes as they unfold over multiple scales (e.g., molecular, cellular, organismal; Fig. 4d). Given that unity and diversity are foundational features of living systems, the development of conceptual and theoretical frameworks guiding empirical studies about student thinking about living systems is long overdue. Such frameworks could be used to synthesize past work, connect researchers from different life science sub-disciplines, and establish a unifying research agenda for BER.

\section{Randomness, probability, and contingency}

Many students and teachers have a tacit awareness that biology is different from the physical sciences. Yet, explicit frameworks illuminating these conceptual similarities and differences are often lacking in biology education (Klymkowsky et al., 2016). The behavior of biological systems is complex for many reasons, although the simultaneous operation of numerous causes each of which produces weak effects is an important one (Lewontin, 2000). Biological systems are also impacted by multiple probabilistic interactions with and among scales (e.g., molecular, cell, organismal, ecological) (Garvin-Doxas \& Klymkowsky, 2008). For these reasons, biological patterns and processes are characterized by "...a plurality of causal factors, combined with probabilism in the chain of events ..." across scales (Mayr, 1997, p. 68). This messy situation often stands in sharp relief to student learning experiences in physics and chemistry, where fewer causes with stronger effects and more deterministic outcomes are encountered (Lewontin, 2000). Given the
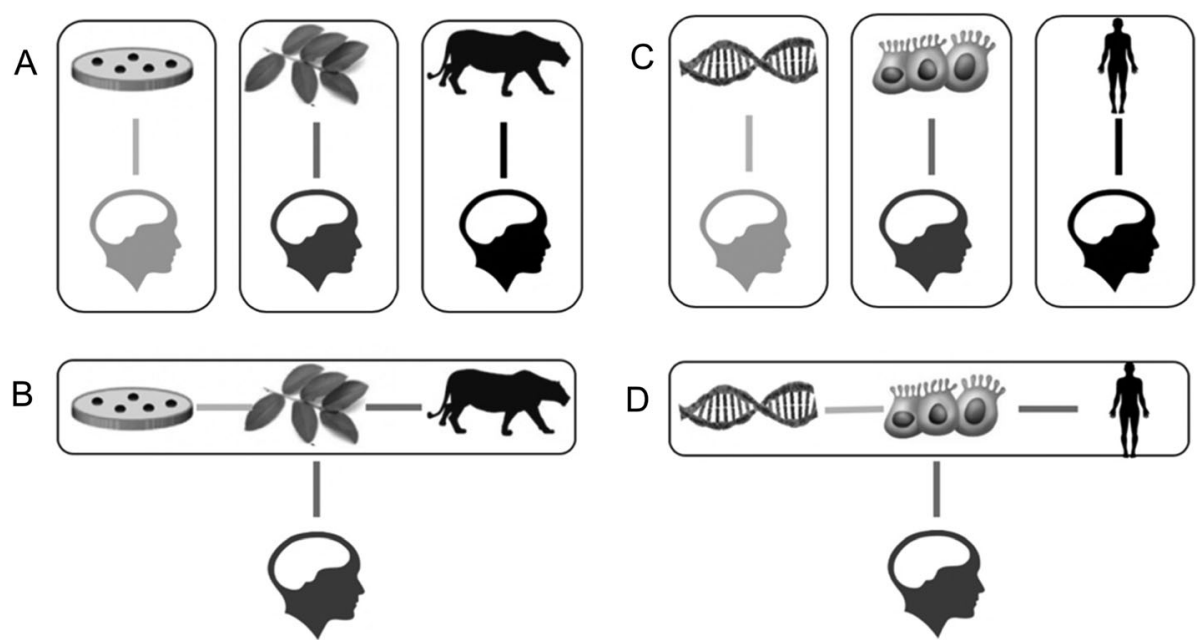

Fig. 4 One example of unity and diversity in biological reasoning. Note that examples using a broader set of scales (e.g., ecosystem) could be utilized. a Within a biological scale (in this case, the scale of organism), reasoning about living systems lacks unification and is organized by taxonomic contexts, experiential instances, and case examples. b Within a biological scale (in this case, the scale of organism) reasoning about living systems is characterized by abstract models transcending organismal type or lineage (i.e. conceptual unity). c Among biological scales (in this case, molecule, cell, organism), reasoning about living systems lacks unification and is organized by macroscopic (organismal), microscopic (cellular), and molecular (biochemical) levels of biological organization. $\mathbf{d}$ Among biological scales (in this case, molecule, cell, organism), reasoning about living systems at is characterized by abstract models linking biological scales (i.e. conceptual unity) 
special properties of biological systems (at least in terms of the topics explored by students), a BER research program exploring how students make sense of randomness, probability, and determinism across lineages and biological scales emerges as an essential consideration (Garvin-Doxas \& Klymkowsky, 2008).

Student learning difficulties with randomness and probability in biology are well established (Garvin-Doxas \& Klymkowsky, 2008). Large numbers of university undergraduates previously exposed to natural selection falsely consider it to be a "random" process (Beggrow and Nehm, 2012); genetic drift misconceptions--many of which are closely tied to ideas of chance--are abundant (Price et al. 2014); and reasoning about osmosis and diffusion, which require thinking about probability at molecular scales, remains challenging for students at advanced levels of biology education (Garvin-Doxas \& Klymkowsky, 2008). Many fundamental but very basic biological phenomena (i.e. in terms of the number of interacting causes within and among levels of organization) pose substantial challenges. But much like the discipline-specific documentation of other learning challenges, difficulties with randomness and probability are often discussed in the context of specific biological concepts (e.g., Punnett squares, Hardy-Weinberg equilibrium) rather than as unifying features of biological systems. What is currently lacking in BER is an organizing framework that cuts across instances (e.g., diffusion, meiosis, selection, drift) and guides systematic review and synthesis of different biology learning challenges relating to randomness and probability.

Student learning difficulties may be traced to many causes, which raises the question of whether there is empirical evidence that probabilistic reasoning is responsible for the aforementioned learning difficulties. Recent work by Fiedler et al. (2019) has quantified the contribution of probabilistic reasoning to biology understanding. In a large sample of university biology students, Fiedler et al. (2019) demonstrated that statistical reasoning (in the contexts of mathematics and evolution) displayed significant and strong associations with knowledge of evolution. Although this result is perhaps unsurprising given previous work (Garvin-Doxas \& Klymkowsky, 2008), it is notable that statistical reasoning was also found to have significant and strong associations with the acceptance of evolution. Fiedler et al. (2019) affirm the significant role of probabilistic thinking in biological reasoning, and open the door to empirical explorations of many other topics in the life sciences. Although Fiedler et al. (2019) do not propose a framework for conceptualizing randomness and probability in the life sciences, they do argue that statistical reasoning is a core feature of reasoning about living systems (as opposed to an ancillary tool for studying living systems). This perspective reformulates the role of statistics in biological competence. Clearly, the development of a conceptual framework focusing on randomness, probability, and contingency could offer great potential for uniting research efforts across biological subdisciplines (e.g., molecular biology, genetics, evolution).

\section{Scale, hierarchy, and emergence}

The hierarchical structure of life, and its corresponding biological scales (e.g., cell, tissue, organ, organism, population, species, ecosystem) are repeatedly acknowledged as important considerations about biological systems in nearly every textbook and classroom. Although most (if not all) biology education programs draw student attention to the concepts of scale and hierarchy, they rarely explore how scale and hierarchy elucidate and problematize the functioning of biological systems. For example, an understanding of the interdependence of patterns and processes across scales (e.g., upward and downward causation) as well as the emergence of novel properties at higher levels (e.g., the whole is more than the sum of its parts), is necessary for making sense of nearly all of the core ideas unifying the life sciences (e.g., information flow, matter and energy transformation, evolution). Yet, a review of the literature reveals that an explicit curriculum for helping students engage in the meaning of this hierarchical arrangement appears lacking.

Extending discussions of the unity and diversity of life (see Fig. 4, above), reasoning about living systems may also display unity or diversity across hierarchical levels. For example, reasoning about living systems may lack unification, and knowledge structures or mental models may be organized by macroscopic (organismal), microscopic (cellular), and molecular (biochemical) levels of biological organization (Fig. 4c). In such cases, knowledge structures and reasoning are bound to particular scales or levels, and conceptual linkages among these scales (e.g., upward and downward causation, emergent properties) may be lacking. Alternatively, reasoning about living systems may be characterized by abstract models unifying biological scales (i.e. conceptual unity) (Fig. 4d). In such cases, knowledge structures and mental models transcend scale and utilize level-specific understanding. The main point is that hierarchical scale is an important aspect of biological reasoning that may facilitate or constrain student understanding. The principles of scale, hierarchy, and emergence are central to biological reasoning, yet BER lacks a robust conceptualization of these concepts and their role in student understanding of living systems. Theoretical and conceptual frameworks for scale, hierarchy, and emergence could help to guide systematic review and synthesis of different biology learning challenges and guide research efforts in BER. 
In summary, this critical review, as well as prior reviews of BER, have found few discipline-specific conceptual or theoretical frameworks for the field (Dirks, 2011; deHaan, 2011). The fragmented disciplinary history and structure of the life sciences (see above) has been a concern noted by eminent biologists and professional organizations for at least 60 years (e.g., NRC, 1958). Despite progress in conceptual unification in the biological sciences, the BER community to a significant degree remains compartmentalized along historical, institutional, and disciplinary boundaries (e.g., microbiology, biochemistry, evolution). Efforts by BER researchers to understand and measure student understanding of living systems have likewise progressed along disciplinary themes, concepts, and topics.

Many core features of living systems offer opportunities for crafting discipline-specific educational frameworks for BER. Given the fragmentation of the life sciences and BER, it is presumptuous and unrealistic for any single scholar or subfield to impose such a framework. Three interconnected themes--unity and diversity; randomness, probability, and contingency; and scale, hierarchy, and emergence-have been identified in prior synthesis efforts and offered as potential starting points for a cross-disciplinary discussion of possible fieldspecific frameworks. Such frameworks are critical to the epistemic foundations of BER. They have immense potential for enriching a wide array of research efforts spanning different subfields, organizing the growing list of student learning difficulties, and building casual frameworks capable of grounding empirical research agendas.

\section{Limitations}

This critical review has identified significant opportunities and challenges for BER. The most pressing opportunity noted throughout this review is the development of discipline-specific conceptual and theoretical frameworks. The absence of explicit disciplinary frameworks raises questions about disciplinary identity (e.g., "What is BER?") and encourages superficial and dissatisfying answers (e.g., "BER studies biology education"). The perspective advanced in this review is that the absence of cognitive and disciplinary frameworks generates epistemic instability (e.g., a-theoretical empiricism) and clouds our ability to rigorously understand student thinking about living systems. There are, however, alternative perspectives on the significance of disciplinespecific frameworks for BER; two are discussed below.

First, if BER-affiliated scholars were to ignore or abandon the National Research Council's (2013) conceptualization and definition of BER (and the broader topic of DBER), then biology-related educational research efforts could easily be subsumed within the field of Science Education (cf. Nehm, 2014). In this case, discipline-focused theoretical frameworks become less of a concern because frameworks from science education could guide epistemic aims and corresponding research agendas. Attention to the unique aspects of biological concepts (e.g., inheritance, photosynthesis, phylogenetics) would fade (but not disappear) and educational frameworks (e.g., socio-cognitive theory, constructivism) would come into sharper focus. This alternative conceptualization foregrounds educational frameworks and backgrounds disciplinary frameworks. The rationale for BER as a standalone field consequently weakens, along with arguments concerning the critical nature of disciplinefocused conceptual frameworks.

A second perspective concerns the necessity of conceptual and theoretical frameworks for BER (and perhaps other scholarly efforts) altogether. Theory building linked to causal explanation is widely-recognized as a central goal of scientific and social-science research (cf. Brigandt, 2016; Rocco \& Plakhotnik, 2009). Some BER scholars, however, do not appear to consider such frameworks as central epistemic features of their work (as indicated by much of the work reviewed here). Indeed, there are numerous examples of implicit or atheoretical hypothesis testing in the BER journals listed in Table 1. This stance minimizes the importance of conceptual or theoretical frameworks in scholarly work, and in so doing eliminates the central concern advanced in this review.

One final and significant limitation of this critical review is that it has adopted a Western, and largely American, perspective. Many of the conclusions drawn are unlikely to generalize to other nations or cultures. It is well known that the structure of biology education research differs around the world (e.g., Indonesia, China, Korea, Germany). Studies of biology learning may be situated within university education departments or biology departments (or combinations thereof). Teacher training in biology may be housed in colleges exclusively devoted to biology education, or departments focusing on general biology education (e.g., medicine, conservation).

International comparison studies (e.g., Ha, Wei, Wang, Hou, \& Nehm, 2019; Rachmatullah, Nehm, Ha, \& Roshayanti, 2018) are likely to offer rich insights into the relationships between biology education research agendas, institutional contexts, and the conceptual and theoretical frameworks used to make sense of student thinking about living systems. Indeed, what are the affordances and constraints of different institutional and epistemic arrangements to knowledge discovery in biology education? Collectively, how could these alternative arrangements enhance our ability to foster deeper understanding of the living world? Further reviews from a broader array of stakeholders will enhance our collective understanding of BER around the world. 


\section{Conclusion}

This critical review examined the challenges and opportunities facing the field of Biology Education Research (BER). Ongoing fragmentation of the biological sciences was identified as a force working in opposition to the development of (i) unifying conceptual frameworks for living systems and (ii) unifying frameworks for understanding student thinking about living systems. Institutional, disciplinary, and conceptual fragmentation of the life sciences aligns with the finding that BER generally lacks unique, unifying, and discipline-focused conceptual or theoretical frameworks. Biology concept inventory research was used to illustrate the central role that conceptual frameworks (both cognitive and disciplinary) play in making sense of student thinking about living systems. Relevant insights from developmental and cognitive psychology were reviewed as potential starting points for building more robust cognitive frameworks, and prior theoretical work by biologists was leveraged to generate possible starting points for discipline-focused frameworks. Three interconnected themes--unity and diversity; randomness, probability, and contingency; and scale, hierarchy, and emergence-were identified as central to thinking about living systems and were linked to ongoing BER research efforts. The review emphasized that the development of conceptual frameworks that account for how learners make sense of similarities and differences within and across living systems as they progress through ontogeny and formal education will help to foster epistemic stability and disciplinary unification for BER.

\section{Abbreviations \\ BER: Biology Education Research; CAT: Computer Adaptive Test; Cl: Concept Inventory; CRISPR: Clustered Regularly Interspaced Short Palindromic Repeats; CTT: Classical Test Theory; DBER: Discipline-Based Education Research; DNA: Deoxyribonucleic Acid; ERIDOB: European Researchers In the Didaktics of Biology; IRT: Item Response Theory; MTF: Multiple True False; NRC: National Research Council; OMC: Ordered Multiple Choice; PULSE: Partnership for Undergraduate Life Science Education; SABER: Society for the Advancement of Biology Education Research}

\section{Acknowledgements}

Not applicable.

\section{Authors' contributions}

$\mathrm{RHN}$ wrote the manuscript. The author read and approved the final manuscript.

\section{Authors' information \\ Not applicable.}

\section{Funding}

Partial funding for this work was provided by the Howard Hughes Medical Institute (HHMI) Inclusive Excellence program.

\section{Availability of data and materials}

Not applicable as this is a review article.

Ethics approval and consent to participate Not applicable.

\section{Consent for publication}

Not applicable.

\section{Competing interests}

The author declares that he/she has no competing interests.

Received: 28 May 2019 Accepted: 8 November 2019

Published online: 02 December 2019

\section{References}

Abraham, J. K., Perez, K. E., \& Price, R. M. (2014). The Dominance Concept Inventory: A Tool for Assessing Undergraduate Student Alternative Conceptions about Dominance in Mendelian and Population Genetics. CBE-Life Sciences Education, 13(2), 349-358.

American Association for the Advancement of Science (AAAS). (2011). Vision and change in undergraduate biology education. Washington, DC, 2011. http:// visionandchange.org/. Accessed 20 Feb 2018.

Au, T., Sidle, A., \& Rollins, K. (1993). Developing an intuitive under-standing of conservation and contamination: Invisible particles as a plausible mechanism. Developmental Psychology, 29, 286-299.

Bassok, M., \& Novick, L. R. (2012). Problem solving. In: The Oxford Handbook of Thinking and Reasoning Edited by Keith J. Holyoak and Robert G. Morrison. Oxford University Press.

Beggrow, E., \& Nehm, R. H. (2012). Students' mental models of evolutionary Causation: Natural Selection and Genetic Drift. Evolution Education and Outreach. https://doi.org/10.1007/s12052-012-0432-z.

Boone, W. J., Staver, J. R., \& Yale, M. S. (2014). Rasch analysis in the human sciences. Dordrecht: Springer.

Brigandt, I. (2016). Why the Difference Between Explanation and Argument Matters to Science Education. Science \& Education, 25. https://doi.org/10.1007/s11191016-9826-6.

Brownell, S. E., Freeman, S., Wenderoth, M. P., \& Crowe, A. J. (2014). BioCore Guide: A Tool for Interpreting the Core Concepts of Vision and Change for Biology Majors. CBE-Life Sciences Education, 13(2), 200-211.

Campbell, C., \& Nehm, R. H. (2013). Evaluating assessment quality in genomics and bioinformatics education research. CBE-Life Sciences Education, 12(3), 530-541. https://doi.org/10.1187/cbe.12-06-0073.

Catley, K. M., \& Novick, L. R. (2009). Digging deep: Exploring college students' knowledge of macroevolutionary time. Journal of Research in Science Teaching, 46(3), 311-332.

Coley, J. D., \& Tanner, K. D. (2012). Common Origins of Diverse Misconceptions: Cognitive Principles and the Development of Biology Thinking. CBE-Life Sciences Education, 11(3), 209-215.

DeHaan R. L. (2011). Education Research in the Biological Sciences: A NineDecade Review. Paper presented at the Second Committee Meeting on the Status, Contributions, and Future Directions of Discipline-Based Education Research, Washington, DC, 2010. www7.nationalacademies.org/bose/DBER DeHaan_October_Paper.pdf. Accessed 21 Mar 2019.

Dirks C. (2011). The Current Status and Future Direction of Biology Education Research. Paper presented at the Second Committee Meeting on the Status, Contributions, and Future Directions of Discipline-Based Education Research, Washington, DC, 2010. www7.nationalacademies.org/bose/DBER_Dirks_ October_Paper.pdf. Accessed 21 Mar 2019.

Dobzhansky, T (1973). Nothing in Biology Makes Sense except in the Light of Evolution. The American Biology Teacher, Vol. 35 No. 3, Mar., 1973; (pp. 125129). https://doi.org/10.2307/4444260.

Driver, R., Squires, A., Rushworth, P., \& Wood-Robinson, V. (1994). Making sense of secondary science: Research into Children's ideas. New York: Routledge.

Fiedler, D., Sbeglia, G. C., Nehm, R. H., \& Harms, U. (2019). How strongly does statistical reasoning influence knowledge and acceptance of evolution? Journal of Research in Science Teaching, 56(9), 1183-1206.

Fisher, K. M., Williams, K. S., \& Lineback, J. E. (2011). Osmosis and Diffusion Conceptual Assessment. CBE-Life Sciences Education, 10(4), 418-429.

Freidenreich, H. B., Duncan, R. G., \& Shea, N. (2011). Exploring middle school students' understanding of three conceptual models in genetics. International Journal of Science Education, 33(17), 2323-2349.

Garvin-Doxas, K., \& Klymkowsky, M. W. (2008). Understanding randomness and its impact on student learning: Lessons from the biology concept inventory (BCI). CBE Life Science Education, 7, 227-233.

Gerard, R. W., \& Stevens, R. B. (1958). Concepts of Biology, National Research Council Publication 560 (). D.C.: National Academy Press. Washington. 
Goldberg, R. F., \& Thompson-Schill, S. L. (2009). Developmental "roots" in mature biological knowledge. Psychological Science, 20(4), 480-487.

Ha, M., \& Nehm, R. H. (2014). Darwin's difficulties and students' struggles with trait loss: Cognitive-historical parallelisms in evolutionary explanation. Science \& Education. https://doi.org/10.1007/s11191-013-9626-1.

Ha, M., Wei, X., Wang, J., Hou, D., \& Nehm, R. H. (2019). Chinese pre-service biology teachers' evolutionary knowledge, reasoning patterns, and acceptance levels. International Journal of Science Education, 41(5), 628-651. https://doi.org/10.1080/09500693.2019.1572936.

Haslam, F., \& Treagust, D. (1987). Diagnosing Secondary Students' Misconceptions of Photosynthesis and Respiration in Plants Using a Two-Tier Multiple-Choice Instrument. Journal of Biological Education, 21. https://doi.org/10.1080/ 00219266.1987 .9654897

Imenda, S. (2014). Is there a conceptual difference between theoretical and conceptual frameworks? Journal of Social Science, 2(38), 185-195.

Inagaki, K., \& Hatano, G. (1991). Constrained person analogy in young children's biological inference. Cognitive Development, 6, 219-231.

Kalas, P., O'Neill, A., Pollock, C., \& Birol, G. (2013). Development of a Meiosis Concept Inventory. CBE - Life Sciences Education, 12(4), 655-664.

Kampourakis, K. (2013). Making sense of evolution. Oxford University Press.

Kargbo, D. B., Hobbs, E. D., \& Erickson, G. L. (1980). Children's beliefs about inherited characteristics. Journal of Biological Education, 14(2), 137-146.

Kelemen, D., \& Rosset, E. (2009). The human function compunction: Teleological explanation in adults. Cognition, 111, 138-143.

Kelemen, D., \& DiYanni, C. (2005). Intuitions About Origins: Purpose and Intelligent Design in Children's Reasoning About Nature. Journal of Cognition and Development, 6(1), 3-31.

Klymkowsky, M. W., Rentsch, J. D., Begovic, E., \& Cooper, M. M. (2016). The design and transformation of biofundamentals: A non-survey introductory evolutionary and molecular biology course. CBE-Life Sciences Education, 15, $\operatorname{ar} 70$.

Lewontin, R. (2000). The triple helix. Harvard University Press.

Mayr, E. (1997). This is biology. New York: Basic Books.

McFarland, J. L., Price, R. M., Wenderoth, M. P., Martinková, P., \& Cliff, W. (2017). Joel Investigating Novice and Expert Conceptions of Genetically Modified Organisms. CBE-Life Sciences Education, 16, 3.

Mead, L. S., Kohn, C., Warwick, A., \& Schwartz, K. (2019). Applying measurement standards to evolution education assessment instruments. Evolution: Education and Outreach, 12, 5. https://doi.org/10.1186/s12052-019-0097-y.

Miller, J. G. (1978). Living Systems. McGraw Hill.

National Research Council (1958). Concepts of Biology. National Academies Press

National Research Council (2001). Knowing what students know: the science and design of educational assessment. Washington, DC: National Academies Press.

National Research Council (2009). The New Biology. Washington, DC: National Academies Press.

National Research Council (2012). Discipline-based education research: Understanding and improving learning in undergraduate science and engineering. Washington, DC: National Academies Press.

National Research Council (2013). NGSS Lead States. Next generation science standards: for states, by states. Washington, DC: The National Academies Press.

National Science Foundation (2019). Re-Integrating Biology. https:// reintegratingbiology.org/. Accessed 5 Nov 2019.

Nehm, R. H. (2014). Discipline-based education research. Science Education., 98(3), 543-546.

Nehm, R. H. (2018). Evolution (chapter 14). In K. Kampourakis, \& M. Reiss (Eds.), Teaching biology in schools: Global issues and trends. Taylor and Francis: Routledge.

Nehm, R. H., Beggrow, E., Opfer, J., \& Ha, M. (2012). Reasoning about natural selection: Diagnosing Contextual competency using the ACORNS instrument. The American Biology Teacher., 74(2).

Nehm, R. H., \& Ha, M. (2011). Item feature effects in evolution assessment. Journal of Research in Science Teaching, 48(3), 237-256.

Nehm, R. H., \& Haertig, H. (2012). Human vs. computer diagnosis of Students' natural selection knowledge: Testing the efficacy of text analytic software. Journal of Science Education and Technology., 21(1), 56-73.

Nehm, R. H., \& Mead, L. (2019). Evolution Assessment. Introduction to the Special Issue. Evolution Education \& Outreach . https://doi.org/10.1186/s12052-0190098-X .

Nehm, R. H., Poole, T. M., Lyford, M. E., Hoskins, S. G., Carruth, L., Ewers, B. E., \& Colberg, P. J. (2009). Does the segregation of evolution in biology textbooks and introductory courses reinforce students' faulty mental models of biology and evolution? Evolution Education and Outreach, 2, 527-532.

Nehm, R. H., \& Ridgway, J. (2011). What do experts and novices "see" in evolutionary problems? Evolution: Education and Outreach, 4(4), 666-679.

Nehm, R. H., \& Schonfeld, I. (2008). Measuring knowledge of natural selection: A comparison of the CINS, and open-response instrument, and oral interview. Journal of Research in Science Teaching, 1131-1160.

Nehm, R. H., \& Schonfeld, I. (2010). The future of natural selection knowledge measurement. Journal of Research in Science Teaching., 47(3), 358-362.

Neumann, I., Neumann, K., \& Nehm, R. (2011). Evaluating instrument quality in science education: Rasch-based analyses of a nature of science test. International Journal of Science Education, 33(10), 1373-1405.

Newman, D. L., Snyder, C. W., Fisk, J. N., \& Wright, L. K. (2016). Development of the Central Dogma Concept Inventory (CDCI) Assessment Tool. CBE-Life Sciences Education, 15, 2.

Opfer, J. E., \& Siegler, R. S. (2004). Revisiting preschoolers' living things concept: A microgenetic analysis of conceptual change in basic biology. Cognitive Psychology, 49, 301-332.

Opfer, J. E., et al. (2012). Cognitive foundations for science assessment design: Knowing what students know about evolution. Journal of Research in Science Teaching, 49(6), 744-777.

Opfer, J. E., Gelman, S. A. (2010). Development of the Animate-Inanimate Distinction. In: Usha Goswami (Ed.). The Wiley-Blackwell Handbook of Childhood Cognitive Development, Second edition.

Partnership for Undergraduate Life Sciences Education (2019). http://www.pulsecommunity.org/. Accessed 21 Mar 2019.

Pfundt, H., \& Duit, R. (1998). Bibliography. Students' Alternative Frameworks and Science Education, (2nd ed.).

Poling, D. A., \& Evans, E. M. (2002). Why do birds of a feather flock together? Developmental change in the use of multiple explanations: Intention, teleology and essentialism. British Journal of Developmental Psychology, 20, 89-112.

Potter, L. M., Bissonnette, S. A., Knight, J. D., Tanner, K. D., O'Dowd, D. K. (2017). Investigating Novice and Expert Conceptions of Genetically Modified Organisms. CBE-Life Sciences Education 16 (3):ar52.

Price, R. M., Andrews, T. C., McElhinny, T. L., Mead, L. S., Abraham, J. K., Thanukos, A., Perez, K. E., Shuster, M. (2014). The Genetic Drift Inventory: A Tool for Measuring What Advanced Undergraduates Have Mastered about Genetic Drift. CBE-Life Sciences Education, 13(1), 65-75.

Rachmatullah, A., Nehm, R.H., Ha, M. Roshayanti, F. (2018). Evolution education in Indonesia: Pre-service biology teachers' evolutionary knowledge levels, reasoning models, and acceptance patterns. Evolution Education around the Globe. (Eds.). Deniz, H. Borgerding, L. springer.

Raman, L., \& Winer, G. A. (2002). Children's and adults' understanding of illness: Evidence in support of a coexistence model. Genetic, Social, and General Psychology Monographs, Washington, 128(4), 325-355.

Reiss, M., \& Kampourakis, K. (2018). Teaching Biology in Schools Global Research, Issues, and Trends. Taylor and Francis.

Rocco, T. S., \& Plakhotnik, M. (2009). Literature reviews, conceptual frameworks, and theoretical frameworks: Terms, functions, and distinctions. Human Resource Development Review, 8(1), 120-130.

Sbeglia, G., \& Nehm, R. H. (2018). Measuring evolution acceptance using the GAENE: Influences of gender, race, degree-plan, and instruction. Evolution Education \& Outreach. https://doi.org/10.1186/s12052-018-0091-9 .

Sbeglia, G., \& Nehm, R. H. (2019). Do you see what I-SEA? A Rasch analysis of the psychometric properties of the Inventory of Student Evolution Acceptance. Science Education. https://doi.org/10.1002/sce.21494.

Schmiemann, P., et al. (2017). Assessment of genetics understanding: Under what conditions do situational features have an impact on measures? Science Education, 26(10), 1161-1191.

Shea, N. A., Duncan, R. G., \& Stephenson, C. (2015). A tri-part model for genetics literacy: Exploring undergraduate student reasoning about authentic genetics dilemmas. Research in Science Education, 45(4), 485-507.

Smith, M. K., Wood, W. B., \& Knight, J. K. (2008). The genetics concept assessment: A new concept inventory for gauging student understanding of genetics. CBELife Sciences Education, 7(4), 422-430.

Smith, M. U. (1983). A comparative analysis of the performance of experts and novices while solving selected classical genetics problems, Unpublished doctoral dissertation (). FL: Florida State University.

Solomon, G., Johnson, S. C., Zaitchik, D., \& Carey, S. (1996). Like father like son: Young children's understanding of how and why offspring resemble their parents. Child Development, 67, 151-171. 
Stefanski, K. M., Gardner, G. E., \& Seipelt-Thiemann, R. L. (2016). Development of a Lac Operon Concept Inventory (LOCI). CBE-Life Sciences Education, 15, 2.

Stewart, J., Cartier, J. L., \& Passmore, P. M. (2005). Developing understanding through model-based inquiry. In M. S. Donovan \& J. D. Bransford (Eds.), How students learn (pp. 515-565). Washington D.C: National Research Council.

Todd, A., et al. (2017). Development and validation of the learning progressionbased assessment of modern genetics (LPA-MG) in a high school context. Science Education, 101(1), 32-65.

Tornabene, R. E., Lavington, E., \& Nehm, R. H. (2018). Testing validity inferences for genetic drift inventory scores using Rasch modeling and item order analyses. Evolution Education \& Outreach., 11(6). https://doi.org/10.1186/s12052-0180082-x.

Wandersee, J. H., \& Schussler, E. E. (1999). The American Biology Teacher, 61(2) $82+84+86$.

Ware, E. A., \& Gelman, S. A. (2014). You get what you need: An examination of purpose-based inheritance reasoning in undergraduates, preschoolers, and biological experts. Cognitive Science, 38(2), 197-243.

Weiss, P. (1958). Introduction, In: Gerard, R.W., Stevens, R. B. (1958). Concepts of Biology. National Research Council Publication 560. D.C.: National Academy Press Washington.

\section{Publisher's Note}

Springer Nature remains neutral with regard to jurisdictional claims in published maps and institutional affiliations.

\section{Submit your manuscript to a SpringerOpen ${ }^{\circ}$ journal and benefit from:}

- Convenient online submission

- Rigorous peer review

- Open access: articles freely available online

High visibility within the field

- Retaining the copyright to your article

Submit your next manuscript at $\boldsymbol{\nabla}$ springeropen.com 